\title{
Considerations for estimating daily intake values of nonpersistent environmental endocrine disruptors based on urinary biomonitoring data
}

\author{
Tue Søeborg, Hanne Frederiksen and Anna-Maria Andersson \\ Department of Growth and Reproduction, GR 5064, Rigshospitalet, Faculty of Health and \\ Medical Sciences, University of Copenhagen, Blegdamsvej 9, DK-2100 Copenhagen, Denmark \\ Correspondence should be addressed to T Søeborg; Email: tue.soeeborg@regionh.dk
}

\begin{abstract}
Human exposure to chemicals may be estimated by back-calculating urinary concentrations resulting from biomonitoring studies if knowledge of the chemical's toxicokinetic properties is available. In this paper, available toxicokinetic data for back-calculating urinary concentrations into daily intake values for bisphenol A (BPA), phthalates, parabens, and triclosan (TCS) are reviewed and knowledge gaps are identified. Human data is evaluated and presented with relevant animal data. Focus is on the recovery of the administered dose, the route of administration, and differences between humans and animals. Two human toxicokinetic studies are currently used to conclude that an oral dose of BPA is recoverable in urine and that no free BPA is present in plasma in spite of several contradicting biominotoring studies. Urinary recovery of an oral dose of phthalates in humans is complicated to assess due to extensive metabolism. In animals using ${ }^{14} \mathrm{C}$-marked phthalates, near-complete recovery is observed. An oral dose of ${ }^{14} \mathrm{C}$-marked parabens is also almost completely recovered in animals. In both humans and animals, however, two unspecific metabolites are formed, which complicates the back-calculation of parabens in humans. The recovery of both oral and dermal TCS in humans has been studied, but due to background levels of TCS, the back-calculation is difficult to perform. In conclusion, due to limited data, reasonable estimates of daily intake values based on urinary data are often not possible to obtain. Several knowledge gaps are identified and new studies are suggested. The route of administration used in toxicokinetic studies often does not match realistic scenarios.
\end{abstract}

Reproduction (2014) $\mathbf{1 4 7} 455-463$

\section{Introduction}

Urinary concentrations of environmental chemicals are often used as a measure of exposure in biomonitoring studies. To be used for regulatory purposes, these urinary concentrations should be converted into daily intake values of the chemicals in question. In order to perform this conversion, knowledge about the toxicokinetic

\footnotetext{
This paper forms part of a special issue of Reproduction on Endocrine Disrupters. This article was presented at the 7 th Copenhagen Workshop on Endocrine Disrupters, 28-31 May 2013. The meeting was supported by the Danish Ministry of the Environment - Environmental Protection Agency as an activity under the Danish Centre on Endocrine Disrupters. Publication of this special issue has been supported by the Society for Reproduction and Fertility. The opinions or views expressed in this special issue are those of the authors, and do not necessarily reflect the opinions or recommendations of the Danish Ministry of the Environment - Environmental Protection Agency or the Society for Reproduction and Fertility. The Guest Editors for this special issue were Anna-Maria Andersson, Hanne Frederiksen, Niels Erik Skakkebæk, Rigshospitalet, Denmark, Kenneth M Grigor, Western General Hospital, Edinburgh, UK and Jorma Toppari, University of Turku, Finland.
}

properties of the compounds needs to be available. That is administration, distribution, metabolism and excretion (the ADME properties). Different chemicals possess different challenges regarding these toxicokinetic properties. There might be exposure via many routes (oral, dermal and by inhalation like for some of the phthalates (Koch et al. 2013)). Some may be distributed to many different tissues in the body like some UV-filters (Søeborg et al. 2006). Some may be converted into biologically active metabolites like paracetamol, as reviewed by Graham et al. (2013) or be metabolised so fast, that only a fraction of the compound is bioavailable as may be the case for bisphenol A (BPA) under certain circumstances (Völkel et al. 2002). Chemicals may also be metabolised locally in the skin like triclosan (TCS) (Moss et al. 2000) and finally, some may bioaccumulate and show limited excretion like some perfluorinated compounds (Olsen et al. 2007) or be excreted through sweat like some of the phthalates (Genuis et al. 2012). A general overview of these processes is presented in Fig. 1. 


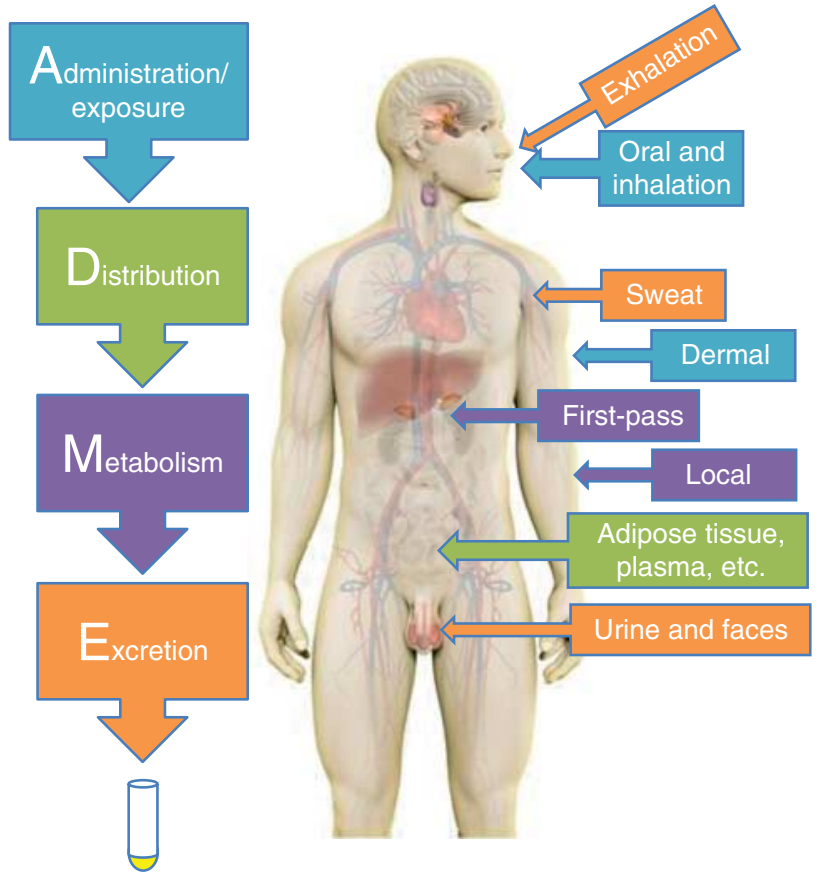

Figure 1 From exposure to excretion, the administration/exposure, distribution, metabolism and excretion (ADME) properties are shown.

In this study, the challenge of converting urinary concentrations of non-persistent environmental endocrine disruptors into daily intake values will be discussed with focus on recovery of the administered dose, the relevance of the route of administration for individual compounds and differences between metabolism in humans and animals. In order to do this, data from human studies will be supplied with relevant data from animal studies. BPA, di- $n$-butyl phthalate (DnBP), di-ethylhexyl phthalate (DEHP), methyl paraben (MeP), $n$-propyl paraben (nPrP) and TCS will be used as model compounds representing different physicochemical properties and different patterns of usage. Furthermore, the need for further research will be identified in order to estimate daily intake values in humans for these compounds based on measured urinary concentrations.

\section{Bisphenol A}

Humans are exposed to BPA from a number of sources, including polycarbonate plastics and epoxy resins, both of which may be used in food contact materials. Furthermore, BPA may be found in thermal and recycled paper and in polyvinyl chloride and various other polymers, as e.g. reviewed by EFSA (2013). As reviewed by Vandenberg et al. (2013), orally administered BPA is rapidly absorbed from the gastrointestinal tract and via first-pass metabolism in the liver converted to BPAglucoronide and to a minor extent BPA-sulfate. Unlike free BPA, both conjugates do not bind to the estrogen receptor (Matthews et al. 2001; Shimizu et al. 2002). They are excreted in urine and can be quantified as BPA following deconjugation in almost every urine sample from different parts of the world (Calafat et al. 2008b; Kim et al. 2011; Frederiksen et al. 2013b).

In order to estimate the recovery of an oral dose of BPA, Völkel et al. (2002) administered 5 mg BPA-d ${ }_{16}$ to healthy volunteers in hard gelatine capsules and quantified the free and the glucoronidated substance in blood and urine samples (see Table 1). In this study, no free BPA was detected in either blood or urine (LODs of $10 \mathrm{nM}(2.3 \mathrm{ng} / \mathrm{ml})$ and $6 \mathrm{nM}(1.4 \mathrm{ng} / \mathrm{ml})$, respectively), but the oral dose was completely recovered as BPAglucoronide in urine within 24-34 h. In a later study by Völkel et al. (2008), BPA- $\mathrm{d}_{16}$ was administered in drinking water and the compound was subsequently quantified in urine samples. Again, no free BPA- $d_{16}$ was detected in urine, whereas the glucoronidated compound could be quantified in amounts corresponding to near-complete recovery of the oral dose (see Table 1 ). No blood samples were analysed in this later study.

By using the results from Völkel et al. (2002, 2008), it may be concluded that quantification of total BPA in urine samples following deconjugation reflects the total exposure to BPA. However, these two studies by Völkel and colleagues are of limited value for evaluating bioavailable BPA, i.e. free BPA that may reach and interact with susceptible receptors in the body. This information is crucial for risk assessment. In the one study where serum samples were analysed (Völkel et al. 2002),

Table 1 Recovery of the administered dose/exposure in urine (human data).

\begin{tabular}{|c|c|c|c|c|}
\hline \multirow[b]{2}{*}{ Compound } & \multicolumn{3}{|c|}{ Administration } & \multirow[b]{2}{*}{ References and comments } \\
\hline & Oral & Dermal & Inhalation & \\
\hline BPA & $\sim 100 \%$ & No data & No data & Völkel et al. (2002, 2008). After 24-34 h \\
\hline \multirow[t]{3}{*}{ DEHP } & $31.0 \pm 5.0 \%$ & No data & No data & Kessler et al. (2012). After $46 \mathrm{~h}$ \\
\hline & $47.1 \pm 8.5 \%$ & & & $\begin{array}{l}\text { Anderson et al. (2011). After } 48 \text { h. MECPP in urine } \\
\text { accounted for } 13.93 \% \text { of the dose }\end{array}$ \\
\hline & $74.3 \%$ & & & $\begin{array}{l}\text { Koch et al. (2005). After } 44 \mathrm{~h} \text {. MCMHP in urine } \\
\text { accounted for } 5.4 \% \text { of the dose }\end{array}$ \\
\hline DnBP & No data & $1.82 \%$ & No data & Janjua et al. (2008). After $24 \mathrm{~h}$ \\
\hline MeP & No data & No data & No data & \\
\hline $\mathrm{nPrP}$ & No data & No data & No data & \\
\hline TCS & $54 \%$ & $5.9 \pm 2.1 \%$ & No data & $\begin{array}{l}\text { Oral: Sandborgh-Englund et al. (2006). After } 96 \mathrm{~h} \text {. } \\
\text { Dermal: Queckenberg et al. (2010). After } 168 \mathrm{~h}\end{array}$ \\
\hline
\end{tabular}


no free BPA was detected. This may be explained by the relative insensitive analytical method applied and the use of hard gelatine capsules for administering BPA, which does not reflect BPA exposure via food. Thus, possible uptake of BPA by absorption through the buccal mucosa cannot be studied using this design. In dogs, the oral (gavage) bioavailability of BPA $(20 \mathrm{mg} / \mathrm{kg})$ has recently been found to be $0.72 \%$, whereas the bioavailability of sublingually administered BPA ( $5 \mathrm{mg} / \mathrm{kg}$ ) has been found to be $70 \%$ (Gayrard et al. 2013). In another study in mice, it was shown that BPA- $d_{6}$ exposure via the diet resulted in higher serum BPA- $d_{6}$ levels than exposure via oral bolus and thus higher levels of bioavailable BPA (Sieli et al. 2011). Indeed, as reviewed by Vandenberg et al. (2007, 2010), several studies have reported levels of free BPA in serum in low nanogram per milliliter range. These reported serum levels of BPA do not seem to correlate with the estimated total exposure of $0.5-0.6 \mu \mathrm{g} / \mathrm{kg}$ per day (with 78-99\% of BPA from dietary sources) recently published by the European Food Safety Agency (EFSA 2013) or the $0.1-0.2 \mu \mathrm{g} / \mathrm{kg}$ per day from dietary sources as estimated by the US Food and Drug Administration (U.S. Food and Drug Administration. Bisphenol A (BPA): Use in Food Contact Application. 6-4-2013. Accessed 14-82013, http://www.fda.gov/newsevents/publichealthfocus/ ucm064437.htm). On the contrary, Taylor etal. (2011) had to administer $400 \mu$ g deuterated BPA $/ \mathrm{kg}$ in feed to adult rhesus monkeys to obtain serum levels of (deuterated) BPA similar to those reported in humans. In the same study, the toxicokinetics of the adult rhesus monkeys, CD-1 mice and the women from the Völkel study (Völkel et al. 2002) were found to be very similar. Thus, exposure to BPA may be via other nondietary routes that to a lesser extent lead to extensive first-pass metabolism, which was also suggested by Stahlhut et al. (2009) after failing to observe decreasing urinary BPA concentrations after $8.5-24 \mathrm{~h}$ of fasting (following an initial decrease in BPA concentrations from 4.5 to $8 \mathrm{~h}$ ). Several potentially relevant nondietary sources of BPA exposure have been identified (e.g., thermal and recycled paper, cigarette filters, and contaminated dust), as reviewed by EFSA (2013) and Vandenberg et al. (2013). The above studies highlight the importance of the route of administration. The vast majority of animal studies for risk assessment are conducted using oral gavage, which does not mimic the way humans are exposed, and thus may underestimate the level of bioavailable BPA in humans.

To the best of our knowledge, no studies exposing healthy volunteers to deuterated BPA have been conducted since the Völkel et al. (2002, 2008), which were hampered by relatively insensitive analytical methods, non-realistic routes of exposure and few study participants. However, in support of the results by Völkel et al. (2002, 2008), a recent comprehensive review using four different methods for estimating human serum concentrations of BPA based on several pharmacokinetic/ toxicokinetic- and biomonitoring studies concluded that serum BPA concentrations should be orders of magnitude lower than levels reported (Teeguarden et al. 2013). Based on their results, the authors in general question reports of measurable BPA in human serum and suggest contamination with BPA during handling and analysis of the samples as a possible explanation of detectable BPA. As evident, results are contradicting. A human study using deuterated BPA spiked in different types of food (acidic, high in fat etc.) and with dermal exposure (e.g. in semisolid topical dosage forms) with subsequent chemical analysis of free and conjugated BPA in urine and serum samples by state-of-the art methods would - in our opinion - add considerably to the understanding of BPA toxicokinetics and thus, aid in the risk assessment conducted by relevant authorities.

\section{Phthalates}

Phthalates are present in a number of products including food packaging materials, toys, cosmetics, medical devices, some types of medicines, paints and building products, as e.g. reviewed by the National Research Council of the National Academies (2008). Phthalates may be classified into two groups based on molecular weight. Low-molecular-weight (LMW) phthalates including DnBP are often used in cosmetics, whereas highmolecular-weight (HMW) phthalates including DEHP can be found in PVC polymer and plastisol applications, as reviewed by Wittassek et al. (2011).

Following oral and topical administration, phthalates are quickly metabolised and excreted in humans (Koch et al. 2005, Koch \& Angerer 2007, Janjua et al. 2008) and because of the ubiquitous distribution in the environment, phthalate metabolites can be quantified in the vast majority of urine samples from many parts of the world (Silva et al. 2004, Irvin et al. 2010, Frederiksen et al. 2011a, Kim et al. 2013).

In a recent study, exposure to DEHP and other HMW phthalates was concluded to be mainly from dietary sources, whereas exposure to DnBP and other LMW phthalates appeared to be from non-dietary sources like personal care products, contaminated dust and indoor air (Koch et al. 2013). This is in accordance with higher amounts of monoethyl phthalate (MEP) (a metabolite of the LMW diethyl phthalate (DEP)) being excreted in adolescents - who supposedly are more exposed to cosmetics and personal care products - than in young children, as reported by Frederiksen et al. (2011a).

For DEP, almost complete recovery of an i.v. or oral dose $(160 \mu \mathrm{g} / \mathrm{kg})$ of ${ }^{14} \mathrm{C}$-DEP in urine and feces was observed in juvenile beagle dogs, with recovery in feces accounting for $3 \%$ of the total dose. After $24 \mathrm{~h}$, MEP accounted for $72-74 \%$ of the recovered dose in urine and three unidentified metabolites were found to account for $11 \%, \leq 1 \%$, and $\leq 1 \%$ of the dose, respectively (Kao et al. 2012). An oral dose of $0.01 \mathrm{mg}$ ${ }^{14} \mathrm{C}-\mathrm{DEHP} / \mathrm{g}$ feed was completely recovered in the feces 
(4\%) and urine $(96 \%)$ of rats (Williams \& Blanchfield 1974), and similar results were obtained for an oral dose of $0.06 \mathrm{mg}{ }^{14} \mathrm{C}$-DnBP/g feed in rats (Tanaka et al. 1978). Thus in animal studies using ${ }^{14} \mathrm{C}$-marked phthalates (DEP, DEHP, and DnBP), complete or near-complete recovery of oral doses was observed predominantly in urine within $48 \mathrm{~h}$ of exposure (Williams \& Blanchfield 1974, Tanaka et al. 1978, Kao et al. 2012).

Oral administration of a single dose of DEHP- $\mathrm{d}_{4}$ in a saccharose solution to four healthy male volunteers with subsequent analysis of the compound and its metabolites in serum and urine resulted in $31.0 \pm 5.0 \%$ of the administered dose being recovered in urine within $46 \mathrm{~h}$ (with $29.1 \pm 4.8 \%$ being accounted for after $22 \mathrm{~h}$ ) (see Table 1). After $24 \mathrm{~h}$, the deuterated compounds were all below or close to the LODs of the analytical method (9 nM) (Kessler et al. 2012). In this study, the metabolite mono-(2-ethyl-5-carboxypentyl) phthalate (MECPP) was not analyzed. However, Anderson et al. (2011) carried out a similar study in 20 healthy volunteers and recovered $47.1 \pm 8.5 \%$ of the administered oral dose of DEHP- $\mathrm{d}_{4}$ in olive oil (as metabolites) in urine after $48 \mathrm{~h}$ including the recovery of $13.9 \%$ of the administered dose as MECPP (see Table 1). Finally, Koch et al. (2005) studied the metabolism and excretion of orally administered DEHP- $\mathrm{d}_{4}$ in butter served on bread at three dose levels in a single healthy volunteer and recovered $74.3 \%$ in urine with no observed differences in metabolism and excretion with dose within $44 \mathrm{~h}$. In this study, five major metabolites of DEHP including mono(2-carboxymethylhexyl) phthalate (MCMHP) (accounting for $5.4 \%$ of the dose) were quantified in urine.

One important question seems to be why nearcomplete recovery of an oral dose of a phthalate may be obtained in animals using ${ }^{14} \mathrm{C}$-markes substances, while only approximately $\sim 50-75 \%$ can be accounted for in humans orally exposed to deuterated phthalates (Koch et al. 2005, Anderson et al. 2011, Kessler et al. 2012)? The obvious answer could be that not all metabolites in urine are detected and quantified, e.g. phthalic acid and hippuric acid, which have been identified in the urine from animals exposed to phthalates (Tanaka et al. 1978, Albro et al. 1982, Nativelle et al. 1999, Silva et al. 2011). Both are nonspecific metabolites of phthalates and other compounds and thus not suited for biomonitoring purposes. Hence, only when using radioactive substances such as ${ }^{14} \mathrm{C}$-labeled phthalates, phthalic acid, and hippuric acid originating from the administered phthalate may be quantified. Another possible explanation could be alternative routes of elimination and/or bioaccumulation. Both LMW and HMW phthalates are lipophilic with estimated $\log P$ values for DnBP and DEHP at 4.7 and 7.4 (Pubchem. http://pubchem.ncbi.nlm.nih.gov/. Accessed 9-102013.), respectively, suggesting their potential for accumulation in adipose tissue. In humans, bioaccumulation of phthalates was indeed suggested, as increasing concentrations of several phthalate metabolites in urine were observed during weight loss in obese, although with no clear distinction between LMW and HMW phthalates (Dirtu et al. 2013). Excretion in other sources than urine was also reported when DEHP and DnBP were quantified in sweat samples more frequently than in serum samples. Metabolites of the two compounds were quantified in sweat, serum, and urine samples, with sweat being an important contributer to the excretion of MEHP and mono-iso-butyl phthalate (MiBP) with 4.6 and 1.4 times higher concentration in sweat than in urine (Genuis et al. 2012). The two DEHP metabolites mono(2-ethyl-5-hydroxyhexyl) phthalate (MEHHP) and mono(2-ethyl-5-oxohexyl) phthalate (MEOHP) were detected in urine but not in sweat and serum.

In both rats and humans, the major metabolite in urine following oral exposure to DnBP was found to be monobutyl phthalate (MnBP), indicating similar metabolism and excretion patterns in the two species (Silva et al. 2007). Likewise, the same metabolites seemed to be present in urine of rats and humans following exposure to DEHP (Silva et al. 2006). Analyzing urine samples from NHANES, Silva et al. (2003) found that MEP accounted for $71 \%$ of the total urinary amount of free and conjugated MEP, whereas MnBP and MEHP, the monoester of DEHP, were found to be excreted in urine predominantly as glucoronidated substances. Thus, different physicochemical properties of phthalates result in differences in metabolism and excretion.

Dermal uptake and subsequent excretion of phthalates in humans was studied by Janjua et al. (2007; 2008). In these studies, whole-body application of semi-solid topical dosage forms containing DEP, DnBP and butyl paraben (BuP) was performed on 26 healthy male volunteers. Following application $\left(2 \mathrm{mg} / \mathrm{cm}^{2}\right)$, MEP and MnBP (and BuP) were quantified in serum and in urine following deconjugation. The amounts recovered in urine within $24 \mathrm{~h}$ after exposure corresponded to 5.79, 1.82 and $0.32 \%$ of the applied dose of DEP, DnBP and BuP, respectively.

Conducting a study in a suitable animal model exposed to similar doses of both ${ }^{14} \mathrm{C}$-marked and deuterated phthalate(s) with subsequent analysis of radioactivity and quantification of known metabolites in urine using stateof-the art analytical methods (e.g. isotope diluted LCMS/MS) would enable not only an evaluation of the amount of metabolites missing in present analytical methods, but also an evaluation of possible bioaccumulation of phthalates and of alternative routes of elimination.

\section{Parabens}

Parabens have been quantified in the vast majority of human urine samples in biomonitoring studies from different parts of the world (Calafat et al. 2010, Frederiksen et al. 2011b, Ma et al. 2013). Humans are exposed to parabens mainly via personal care products and cosmetics, as reviewed e.g. by Darbre \& Harvey (2008), but parabens 
may also be present in food (Liao et al. 2013) and in medicinal products (Ursino et al. 2011).

By oral gavage, Mathews et al. (2012) exposed rats to ${ }^{14} \mathrm{C}$-BuP at three dose levels and recovered $83-85 \%$ of the radioactive dose in urine and $3-6 \%$ in feces within $72 \mathrm{~h}$. Faster excretion but similar levels of recovery in urine and feces were observed $72 \mathrm{~h}$ after i.v. exposure to $10 \mathrm{mg} / \mathrm{kg}$. Following dermal exposure $(72 \mathrm{~h})$ to 10 and $100 \mathrm{mg} / \mathrm{kg}, 21$ and $39 \%$ of the dose were recovered in skin (unabsorbed dose), respectively, and 16 and $43 \%$ of the dose were recovered in the dose-site skin, respectively. At the dermal doses of 10 and $100 \mathrm{mg} / \mathrm{kg} 46$ and $7 \%$, respectively, was recovered in urine. These results indicate that the absorption capacity through the skin becomes saturated. The authors furthermore studied BuP metabolism in vitro using rat and human hepatocytes. In both species, an unspecific compound, p-hydroxybenzoic acid (HBA), was identified as the main metabolite after $5 \mathrm{~h}$ of incubation with $92-100$ and $78-84 \%$ of the dose being converted to HBA in rats and humans, respectively. In human hepatocytes, another unspecific metabolite, $p$-hydroxyhippuric acid (HHA), accounted for $16-22 \%$. Finally, BuP metabolites in rat urine were identified using LC-MS/MS. The major metabolites were HBA and HHA following i.v. and oral exposure to $10 \mathrm{mg}$ ${ }^{14} \mathrm{C}-\mathrm{BuP} / \mathrm{kg}$. However, different amounts were observed depending on the route of exposure, with HHA being the major metabolite following i.v. administration and HBA and butyl-containing metabolites being the major metabolites following oral exposure. Apart from HBA and HHA, several other urinary metabolites were identified, but the amounts of these metabolites including free, sulfated, and glucoronidated BuP were not quantified (Mathews et al. 2012). A similar study in rats using ${ }^{14} \mathrm{C}-\mathrm{MeP},-\mathrm{nPrP}$, and -BuP has recently been conducted (Aubert et al. 2012): following oral exposure by gavage, recovery of the administered dose was found to be similar for the three compounds and the results was comparable to the findings of Mathews et al. (2012) with complete recovery (urine, feces, and cage wash) after $168 \mathrm{~h}$. Following dermal administration, systemic exposure was found to be highest for the short-chainlength $\mathrm{MeP}$ and lowest for the long-chain-length BuP. Urinary excretion of radioactivity following dermal application of $100 \mathrm{mg} / \mathrm{kg}$ was around $20 \%$ for MeP and $\mathrm{nPrP}$ and around $26 \%$ for BuP after $168 \mathrm{~h}$.

Also in human, parabens are readily hydrolyzed to HBA and $\mathrm{HHA}$ and conjugated with glucoronic and sulfuric acid before excretion, as reviewed by Soni et al. (2005). In a biomonitoring study, Ye et al. (2006) quantified free, glucoronidated and sulfated MeP (but not HBA and HHA) in urine samples from 100 volunteers and found the three substances to account for 5, 28 and $67 \%$ of the total amount of excreted MeP and MEP conjugates, respectively. Likewise, free, glucoronidated and sulfated $\mathrm{nPrP}$ accounted for 2, 43 and $55 \%$ of the total amount of excreted $\mathrm{nPrP}$ and $\mathrm{nPrP}$ conjugates, respectively.
Following five daily whole-body applications $\left(2 \mathrm{mg} / \mathrm{cm}^{2}\right)$ of a semi-solid topical dosage form containing 2\% w/w BuP (and DnBP and DEP) corresponding to an average daily dose of $10 \mathrm{mg} / \mathrm{kg}$ BuP to male healthy volunteers, free and glucoronidated BuP was quantified in urine corresponding to $0.32 \%$ of the applied dose (Janjua et al. 2008).

As described earlier, regardless of the route of exposure (oral, topical, or i.v.) a dose of one or more parabens seems to be almost completely recoverable in urine and feces (and in the skin after dermal application). The problem is, however, that HBA and HHA, which are the major urinary metabolites of parabens in rats and after metabolism by rat and human hepatocytes in vitro, are not specific for parabens and thus are not useful for biomonitoring purposes. However, following exposure to parabens, small amounts of the dose can be detected as the parent compound in urine in almost every sample analyzed, and thus, quantification of free and conjugated parabens in urine samples could provide a basis for estimating the daily intake in humans. Unfortunately, it is presently not known at which ratios HBA, HHA, free, and conjugated parabens are excreted in urine following oral and dermal exposure, which makes this kind of backcalculation impossible. To the best of our knowledge, the study by Janjua et al. (2008) is the only study where recovery of a dose of a paraben in humans has been estimated based on the quantification of the free and conjugated compound in urine. In this study, only $0.32 \%$ of the dermally applied dose was recovered in urine as the free and glucoronidated compound. However, as shown by Mathews et al. (2012) in rats, a large fraction of a topically applied dose corresponding to the dose used by Janjua et al. (2008) was recovered in skin as unabsorbed dose $(21 \%)$, and thus, this needs to be taken into account when trying to back-calculate the concentration of paraben found in urine into an estimated intake/uptake. To obtain valuable knowledge for doing this back-calculation, a study using realistic concentrations of parabens in various topical dosage forms applied to healthy volunteers could be carried out. Subsequently, quantification of free and conjugated parabens in urine should be done, as well as quantification of unabsorbed parabens at the dose-site (appropriate use of an animal or an ex vivo model could prove useful for this part of the study). To obtain information about the ratios of metabolites in urine, studies such as the ones performed by Aubert et al. (2012) and Mathews et al. (2012) but with detailed quantification of the excreted metabolites would be very useful.

\section{Triclosan}

TCS is extensively used as an antimicrobial agent in a variety of products such as toothpaste, disinfectants, detergents, soaps, fabrics, mouthwash, and veterinary, industrial, other household and personal care products, 
as reviewed e.g. by Dann \& Hontela (2011). Urinary concentrations of TCS have been measured in samples from many parts of the world, and detectable amounts of TCS were found in $74.6 \%$ of samples from the USA (Calafat et al. 2008a), in $80 \%$ of samples from Denmark (Frederiksen et al. 2013b) and in 92.6\% of samples from Korea (Kim et al. 2011).

Topically applied TCS permeates human skin with some metabolism taking place locally. Free TCS and the glucoronic- and sulfuric acid-conjugated TCS were found following permeation through human skin in vitro (Moss et al. 2000). In the same study, more than $50 \%$ of a topically applied dose of ${ }^{3} \mathrm{H}$-TCS to rats was recovered in the stratum corneum and in the rinseoff of the skin after $24 \mathrm{~h}$ of exposure. Following topical application of approximately $20 \mathrm{mg}$ TCS/ $\mathrm{kg}$ to the skin of healthy volunteers for $12 \mathrm{~h}$ (ended by washing off excess cream), $5.9 \%$ of the dose was recovered in urine within $168 \mathrm{~h}$ (4.9\% recovered within $48 \mathrm{~h}$ ) (Queckenberg et al. 2010) (see Table 1). This is in accordance with previous findings reported by Moss et al. (2000), and with the view of the Scientific Committee on Consumer Products, which states that the amount of the dose absorbed under normal use conditions in humans (topically or when using toothpaste) is assumed to be $5-10 \%$ (European Commission Health and Consumer Protection Directorate-General 2009). This is also in line with the results of Lin (2000), who found that after the use of TCS-containing mouthwash, $7.33 \%$ of the dose was absorbed through the buccal mucosa.

Following a single oral dose of $4 \mathrm{mg}$ TCS (in mouthwash) in humans, 54\% was recovered as free and glucoronidated TCS in urine within four days (with the vast majority of the dose being excreted within $24 \mathrm{~h}$ ) (Sandborgh-Englund et al. 2006; see Table 1). Calculations in the study were difficult due to baseline levels of TCS being present in all participants in spite of a 6-day wash-out period before the exposure. Unidentified sources of TCS exposure most likely explain the TCS background levels. In rats in vivo, TCS is metabolized predominantly by glucoronidation, sulfation, and hydroxylation, with the end-products of these three processes being the only metabolites detected in urine following oral exposure to $5 \mathrm{mg} / \mathrm{kg}$ (Wu et al. 2010).

A daily intake of the total amount of TCS (free and conjugated) that has entered the body based on the quantification of free and conjugated TCS in urine can be estimated with the data currently available (described above). With humans being exposed to TCS from a variety of products and via different routes of exposure (oral and dermal and possibly also through dust (Fan et al. 2010)) with different grades of absorption, the bioavailable dose (free TCS in plasma), however, is hard to estimate based on urinary measurements due to likely differences in metabolism and avoidance of first-pass metabolism dependent of the routes of exposure.

\section{Discussion and conclusions}

In this paper, the ADME properties of selected nonpersistent environmental endocrine disruptors with different physicochemical properties and different use patterns have been reviewed with the purpose of converting urinary concentrations into estimated daily intake values. As can be seen from the above, this is in many cases not an easy task and in the following, a few general issues will be discussed.

Conducting studies using oral gavage as the route of administration is an example of a design that may not reflect the way humans are exposed to chemicals (with the notable exception of phthalate exposure via enteric coated medicinal capsules (Hauser et al. 2004)). In these studies, absorption of the chemical is exclusively taking place from the gastrointestinal tract, where the chemical via vena portae is transported to the liver and undergoes first-pass metabolism, which normally greatly reduces the toxicity of a chemical and increases the rate of excretion. Parenterally administered chemicals avoid first-pass metabolism and may thus enter the systemic circulation and relevant tissues in the body as the parent compound. However, in the vast majority of animal studies, the concentration of the administered chemical and/or its metabolites in serum or urine following exposure to a specific dose is not quantified. If a toxicological effect is observed (or is not observed) no connection can be made from the dose given to the animal.

BPA may be used as an example to highlight the importance of including routes of administration other than oral for assessing human exposure to nonpersistent environmental endocrine disruptors. According to relevant authorities, human exposure to BPA occurs mainly via the diet (EFSA 2013, U.S. Food and Drug Administration. Bisphenol A (BPA): Use in Food Contact Application. 6-4-2013. Accessed 14-8-2013, http:// www.fda.gov/newsevents/publichealthfocus/ucm0644 $37 . \mathrm{htm}$ ) with estimated total daily intakes of $0.1-0.6 \mu \mathrm{g} /$ $\mathrm{kg}$ per day. These estimates do not seem to correlate with the observations made by Stahlhut et al. (2009) of stabilizing levels of urinary excreted BPA after fasting, and with the results reported by Taylor et al. (2011), who fed rhesus monkeys $400 \mu \mathrm{g} \mathrm{BPA} / \mathrm{kg}$ per day to obtain serum levels of free BPA comparable with reported concentrations of free BPA in human serum (Vandenberg et al. 2010). It should be noted that the recent EFSA draft scientific opinion on BPA (EFSA 2013) does not estimate free and thus bioavailable BPA and states that this conversion step needs to be considered in the subsequent step of risk characterization of BPA. The above findings thus indicate non-identified, significant alternative routes of exposure and/or limited non-dietary exposure leading to very high bioavailability of BPA. Likewise, following a six-day wash-out period where all identifiable sources of TCS were avoided, TCS was 
still present in urine and plasma of healthy volunteers (Sandborgh-Englund et al. 2006).

The available human data on the metabolism of chemicals is to a large extent based on studies on healthy adult volunteers, which may not reflect the situation in special and/or vulnerable populations. Indeed, it has recently been shown that the metabolism of DEHP and di-iso-nonyl phthalate (DiNP) changed dramatically with postnatal age in newborns during the first year of life (unpublished results). In the same study, it was also shown that preterm babies may be highly exposed to DEHP, DiNP, and butylbenzyl phthalate via medical devices in hospital settings. Persons with filaggrin gene loss-of-function mutations $(7.5 \%$ of the study population), which is associated with facilitated transfer of allergens across the epidermis, constitute another special but widespread population. Male carriers of the filaggrin-mutation have been shown to excrete up to $33 \%$ higher amounts of 14 phthalate metabolites in their urine compared to men with a normal barrier function of the skin indicating high exposure to phthalates via the dermal route of this population (Joensen et al. 2013). Both these studies investigated phthalates, but the observed special metabolism in babies and presumed increased uptake through the skin of persons with filaggrin gene loss-of-function mutations are likely also to apply to other chemicals such as the one reviewed in this paper. These results therefore highlight the need for special attention toward studies designed to take into account special populations and special circumstances. In risk assessment, safety factors are applied to cover inter- and intra-species differences, e.g. between rat and human and between different subpopulations, respectively. Thus, newborns and carriers of the filaggrin-mutation should in theory already be taken into consideration when risks are assessed. However, data from well-conducted studies in relevant, vulnerable sub-populations such the one described above would always add to the quality of the risk assessment and thus should be performed when possible.

Biomonitoring studies to a large extent rely on quantitative analyses of urine samples in order to estimate human exposure to various chemicals. As evident from Table 1, not much information is available on the urinary recovery of an administered dose of the nonpersistent environmental endocrine disruptors discussed in this paper and more dedicated studies are needed to fill these identified knowledge gaps. The results of these studies will enable us to provide better exposure estimates from biomonitoring data for use in human risk assessment.

\section{Declaration of interest}

The authors declare that there is no conflict of interest that could be perceived as prejudicing the impartiality of the research reported.

\section{Funding}

This article is based on work presented at the 7th Copenhagen Workshop on Endocrine Disrupters, which was supported by the Danish Ministry of the Environment - Environmental Protection Agency. Publication of this special issue was supported by the Society for Reproduction and Fertility. Anna-Maria Andersson is the leader of Centre on Endocrine Disrupters (www.cend.dk), which is a Danish government initiative. The Centre is financially administrated by the Danish EPA and followed by a steering group appointed by the Danish EPA. Tue Søeborg, Hanne Frederiksen, and Anna-Maria Andersson have all been involved in projects run under and financed by the Centre on Endocrine Disrupters. The National Center on Endocrine Disruptors under the Danish Environmental Protection Agency, MST-621-00062.

\section{References}

Albro PW, Jordan ST, Schroeder JL \& Corbett JT 1982 Chromatographic separation and quantitative determination of the metabolites of di-(2-ethylhexyl) phthalate from urine of laboratory animals. Journal of Chromatography. A 244 65-79. (doi:10.1016/S0021-9673(00)80123-5)

Anderson WA, Castle L, Hird S, Jeffery J \& Scotter MJ 2011 A twentyvolunteer study using deuterium labelling to determine the kinetics and fractional excretion of primary and secondary urinary metabolites of di-2-ethylhexylphthalate and di-iso-nonylphthalate. Food and Chemical Toxicology 49 2022-2029. (doi:10.1016/j.fct.2011.05.013)

Aubert N, Ameller T \& Legrand JJ 2012 Systemic exposure to parabens: pharmacokinetics, tissue distribution, excretion balance and plasma metabolites of $\left[{ }^{14} \mathrm{C}\right]$-methyl-, propyl- and butylparaben in rats after oral, topical or subcutaneous administration. Food and Chemical Toxicology 50 445-454. (doi:10.1016/j.fct.2011.12.045)

Calafat AM, Xiaoyun Y, Lee-Yang W, Reidy JA \& Needham LL 2008a Urinary concentrations of triclosan in the U.S. population: 2003-2004. Environmental Health Perspectives 116 303-307. (doi:10.1289/ehp. 10768)

Calafat AM, Ye X, Wong L-Y, Reidy JA \& Needham LL 2008b Exposure of the U.S. population to bisphenol A and 4-tertiary-octylphenol: $2003-$ 2004. Environmental Health Perspectives 116 39-44. (doi:10.1289/ ehp.10753)

Calafat AM, Xiaoyun Y, Lee-Yang W, Bishop AM \& Needham LL 2010 Urinary concentrations of four parabens in the U.S. population: NHANES 2005-2006. Environmental Health Perspectives 118 679-685. (doi:10.1289/ehp.0901560)

Dann A \& Hontela A 2011 Triclosan: environmental exposure, toxicity and mechanisms of action. Journal of Applied Toxicology 31 285-311. (doi:10.1002/jat.1660)

Darbre PD \& Harvey PW 2008 Paraben esters: review of recent studies of endocrine toxicity, absorption, esterase and human exposure, and discussion of potential human health risks. Journal of Applied Toxicology 28 561-578. (doi:10.1002/jat.1358)

Dirtu AC, Geens T, Dirinck E, Malarvannan G, Neels H, Van Gaal L, Jorens PG \& Covaci A 2013 Phthalate metabolites in obese individuals undergoing weight loss: urinary levels and estimation of the phthalates daily intake. Environment International 59 344-353. (doi:10.1016/ j.envint.2013.06.023)

EFSA 2013 Draft scientific opinion on the risks to public health related to the presence of bisphenol A (BPA) in foodstuffs - Part: exposure assessment.

European Commission Health and Consumer Protection DirectorateGeneral 2009 SCCP (Scientific Committee on Consumer Products), Opinion on triclosan, 21 January 2009.

Fan X, Kubwabo C, Rasmussen P \& Jones-Otazo H 2010 Simultaneous quantitation of parabens, triclosan, and methyl triclosan in indoor house dust using solid phase extraction and gas chromatographymass spectrometry. Journal of Environmental Monitoring 12 1891-1897. (doi:10.1039/c0em00189a) 
Frederiksen H, Aksglaede L, Sorensen K, Skakkebaek NE, Juul A \& Andersson AM 2011a Urinary excretion of phthalate metabolites in 129 healthy Danish children and adolescents: estimation of daily phthalate intake. Environmental Research 111 656-663. (doi:10.1016/j.envres. 2011.03.005)

Frederiksen H, Jørgensen N \& Andersson AM 2011b Parabens in urine, serum and seminal plasma from healthy Danish men determined by liquid chromatography-tandem mass spectrometry (LC-MS/MS). Journal of Exposure Science and Environmental Epidemiology 21 262-271. (doi:10.1038/jes.2010.6)

Frederiksen H, Aksglaede L, Sorensen $K$, Nielsen O, Main KM, Skakkebaek NE, Juul A \& Andersson AM 2013a Bisphenol A and other phenols in urine from Danish children and adolescents analyzed by isotope diluted TurboFlow-LC-MS/MS. International Journal of Hygiene and Environmental Health 216 710-720. (doi:10.1016/j.ijheh. 2013.01.007)

Frederiksen H, Nielsen JK, Mørck TA, Hansen PW, Jensen JF, Nielsen O, Andersson AM \& Knudsen LE 2013b Urinary excretion of phthalate metabolites, phenols and parabens in rural and urban Danish motherchild pairs. International Journal of Hygiene and Environmental Health 216 772-783. (doi:10.1016/j.ijheh.2013.02.006)

Gayrard V, Lacroix M, Collet S, Bousquet-Melou A, Toutain P-L \& Picard-Hagen N 2013 High bioavailability of bisphenol a from sublingual exposure. Environmental Health Perspectives 121 951-956. (doi:10.1289/ehp.1307424R)

Genuis S, Beesoon S, Lobo R \& Birkholz D 2012 Human elimination of phthalate compounds: Blood, Urine, and Sweat (BUS) Study. Scientific World Journal 2012 Article ID 615068. (doi:10.1100/2012/615068)

Graham G, Davies M, Day R, Mohamudally A \& Scott K 2013 The modern pharmacology of paracetamol: therapeutic actions, mechanism of action, metabolism, toxicity and recent pharmacological findings. Inflammopharmacology 21 201-232. (doi:10.1007/s10787-013-0172-x)

Hauser R, Duty S, Godfrey-Bailey L \& Calafat AM 2004 Medications as a source of human exposure to phthalates. Environmental Health Perspectives 112 751-753. (doi:10.1289/ehp.6804)

Irvin EA, Calafat AM, Silva MJ, Aguilar-Villalobos M, Needham LL, Hall DB, Cassidy B \& Naeher LP 2010 An estimate of phthalate exposure among pregnant women living in Trujillo, Peru. Chemosphere 80 1301-1307. (doi:10.1016/j.chemosphere.2010.06.048)

Janjua NR, Mortensen GK, Andersson AM, Kongshoj B \& Wulf HC 2007 Systemic uptake of diethyl phthalate, dibutyl phthalate, and butyl paraben following whole-body topical application and reproductive and thyroid hormone levels in humans. Environmental Science \& Technology 41 5564-5570. (doi:10.1021/es0628755)

Janjua NR, Frederiksen H, Skakkebaek NE, Wulf HC \& Andersson AM 2008 Urinary excretion of phthalates and paraben after repeated whole-body topical application in humans. International Journal of Andrology 31 118-130. (doi:10.1111/j.1365-2605.2007.00841.x)

Joensen UN, Jørgensen N, Meldgaard $M$, Frederiksen $H$, Andersson AM, Menné T, Johansen JD, Carlsen BC, Stender S \& Szecsi PB 2013 Increased urinary levels of phthalate metabolites in carriers of the filaggrin gene null mutation. Environmental Health Perspectives. (doi:10. 1289/ehp.1306720)

Kao M, Ruoff B, Bower N, Aoki T, Smart C \& Mannens G 2012 Pharmacokinetics, metabolism and excretion of ${ }^{14} \mathrm{C}$-monoethyl phthalate (MEP) and ${ }^{14} \mathrm{C}$-diethyl phthalate (DEP) after single oral and IV administration in the juvenile dog. Xenobiotica 42 389-397. (doi:10.3109/00498254.2011.627478)

Kessler W, Numtip W, Völkel W, Seckin E, Csanády G, Pütz C, Klein D, Fromme H \& Filser JG 2012 Kinetics of di(2-ethylhexyl) phthalate (DEHP) and mono(2-ethylhexyl) phthalate in blood and of DEHP metabolites in urine of male volunteers after single ingestion of ring-deuterated DEHP. Toxicology and Applied Pharmacology 264 284-291. (doi:10.1016/j.taap.2012.08.009)

Kim K, Park H, Yang W \& Lee JH 2011 Urinary concentrations of bisphenol $A$ and triclosan and associations with demographic factors in the Korean population. Environmental Research 111 1280-1285. (doi:10.1016/ j.envres.2011.09.003)

Kim M, Song NR, Choi JH, Lee J \& Pyo H 2014 Simultaneous analysis of urinary phthalate metabolites of residents in Korea using isotope dilution gas chromatographymass spectrometry. Science of the Total Environment 470-471 1408-1413. (doi:10.1016/j.scitotenv.2013.07.037)
Koch HM \& Angerer J 2007 Di-iso-nonylphthalate (DINP) metabolites in human urine after a single oral dose of deuterium-labelled DINP. International Journal of Hygiene and Environmental Health 210 9-19. (doi:10.1016/j.ijheh.2006.11.008)

Koch HM, Bolt HM, Preuss R \& Angerer J 2005 New metabolites of di(2-ethylhexyl)phthalate (DEHP) in human urine and serum after single oral doses of deuterium-labelled DEHP. Archives of Toxicology $\mathbf{7 9}$ 367-376. (doi:10.1007/s00204-004-0642-4)

Koch HM, Lorber M, Christensen KLY, Pälmke C, Koslitz S \& Brüning T 2013 Identifying sources of phthalate exposure with human biomonitoring: results of a $48 \mathrm{~h}$ fasting study with urine collection and personal activity patterns. International Journal of Hygiene and Environmental Health 216 672-681. (doi:10.1016/j.ijheh.2012.12.002)

Liao C, Liu F \& Kannan K 2013 Occurrence of and dietary exposure to parabens in foodstuffs from the United States. Environmental Science \& Technology 47 3918-3925. (doi:10.1021/es400724s)

Lin YJ 2000 Buccal absorption of triclosan following topical mouthrinse application. American Journal of Dentistry 13 215-217.

Ma WL, Wang L, Guo Y, Liu LY, Qi H, Zhu NZ, Gao CJ, Li YF \& Kannan K 2013 Urinary concentrations of parabens in Chinese young adults: implications for human exposure. Archives of Environmental Contamination and Toxicology 65 611-618. (doi:10.1007/s00244-013-9924-2)

Mathews J, Brown S, Patel P, Black S, Banks T, Etheridge A, Fennell T, Snyder R, Blystone CR \& Waidyanatha S 2012 Metabolism and disposition of $\left[{ }^{14} \mathrm{C}\right] n$-butyl-p-hydroxybenzoate in male and female Harlan Sprague Dawley rats following oral administration and dermal application. Xenobiotica 43 169-181. (doi:10.3109/00498254.2012.702935)

Matthews JB, Twomey K \& Zacharewski TR 2001 In vitro and in vivo interactions of bisphenol a and its metabolite, bisphenol a glucuronide, with estrogen receptors $\alpha$ and $\beta$. Chemical Research in Toxicology 14 149-157. (doi:10.1021/tx0001833)

Moss T, Howes D \& Williams FM 2000 Percutaneous penetration and dermal metabolism of triclosan (2,4,4'-trichloro-2'-hydroxydiphenyl ether). Food and Chemical Toxicology 38 361-370. (doi:10.1016/ S0278-6915(99)00164-7)

National Research Council 2008 Phthalates and cumulative risk assessment. The tasks ahead. Washington, DC, USA: The National Academies Press.

Nativelle C, Picard K, Valentin I, Lhuguenot JC \& Chagnon MC 1999 Metabolism of $n$-butyl benzyl phthalate in the female wistar rat. Identification of new metabolites. Food and Chemical Toxicology 37 905-917. (doi:10.1016/S0278-6915(99)00071-X)

Olsen GW, Burris JM, Ehresman DJ, Froelich JW, Seacat AM, Butenhoff JL \& Zobel LR 2007 Half-life of serum elimination of perfluorooctanesulfonate, perfluorohexanesulfonate, and perfluorooctanoate in retired fluorochemical production workers. Environmental Health Perspectives 115 1298-1305. (doi:10.1289/ehp.10009)

Queckenberg C, Meins J, Wachall B, Doroshyenko O, Tomalik-Scharte D, Bastian B, Abdel-Tawab M \& Fuhr U 2010 Absorption, pharmacokinetics, and safety of triclosan after dermal administration. Antimicrobial Agents and Chemotherapy 54 570-572. (doi:10.1128/AAC.00615-09)

Sandborgh-Englund G, Adolfsson-Erici M, Odham G \& Ekstrand J 2006 Pharmacokinetics of triclosan following oral ingestion in humans. Journal of Toxicology and Environmental Health. Part A 69 1861-1873. (doi:10.1080/15287390600631706)

Shimizu M, Ohta K, Matsumoto Y, Fukuoka M, Ohno Y \& Ozawa S 2002 Sulfation of bisphenol A abolished its estrogenicity based on proliferation and gene expression in human breast cancer MCF-7 cells. Toxicology in Vitro 16 549-556. (doi:10.1016/S0887-2333(02)00055-3)

Sieli P, Jašarevic E, Warsak D, Mao J, Ellersieck M, Liao C, Kannan K, Collet S, Toutain P-L, vom Saal FS et al. 2011 Comparison of serum bisphenol A concentrations in mice exposed to bisphenol A through the diet versus oral bolus exposure. Environmental Health Perspectives 119 1260-1265. (doi:10.1289/ehp.1003385)

Silva M, Barr D, Reidy J, Kato K, Malek N, Hodge C, Hurtz D III, Calafat A, Needham L \& Brock J 2003 Glucuronidation patterns of common urinary and serum monoester phthalate metabolites. Archives of Toxicology 77 561-567. (doi:10.1007/s00204-003-0486-3)

Silva MJ, Barr D, Reidy JA, Malek N, Hodge C, Caudill S, Brock J, Needham LL \& Calafat AM 2004 Urinary levels of seven phthalate metabolites in the U.S. population from the National Health and Nutrition Examination Survey (NHANES) 1999-2000. Environmental Health Perspectives 112 331-338. (doi:10.1289/ehp.6723) 
Silva MJ, Samandar E, Preau J, Needham LL \& Calafat AM 2006 Urinary oxidative metabolites of di(2-ethylhexyl) phthalate in humans. Toxicology 219 22-32. (doi:10.1016/j.tox.2005.10.018)

Silva MJ, Samander E, Reidy JA, Hauser R, Needham LL \& Calafat AM 2007 Metabolite profiles of di- $n$-butyl phthalate in humans and rats. Environmental Science \& Technology 41 7576-7580. (doi:10.1021/es071142x)

Silva MJ, Furr J, Samandar E, Preau J, Gray LE, Needham LL \& Calafat AM 2011 Urinary and serum metabolites of di-n-pentyl phthalate in rats. Chemosphere 82 431-436. (doi:10.1016/j.chemosphere.2010.09.052)

Søeborg T, Ganderup NC, Kristensen JH, Bjerregaard P, Pedersen KL, Bollen P, Hansen SH \& Halling-Sørensen B 2006 Distribution of the UV filter 3-benzylidene camphor in rat following topical application. Journal of Chromatography. B 834 117-121. (doi:10.1016/j.jchromb.2006.02.026)

Soni MG, Carabin IG \& Burdock GA 2005 Safety assessment of esters of p-hydroxybenzoic acid (parabens). Food and Chemical Toxicology 43 985-1015. (doi:10.1016/j.fct.2005.01.020)

Stahlhut R, Welshons WV \& Swan S 2009 Bisphenol A data in NHANES suggest longer than expected half-life, substantial nonfood exposure, or both. Environmental Health Perspectives 117 784-789. (doi:10.1289/ ehp.0800376)

Tanaka A, Matsumoto A \& Yamaha T 1978 Biochemical studies on phthalic esters. III. Metabolism of dibutyl phthalate (DBP) in animals. Toxicology 9 109-123. (doi:10.1016/0300-483X(78)90036-7)

Taylor J, vom Saal FS, Welshons WV, Drury B, Rottinghaus G, Hunt PA, Toutain P-L, Laffont C \& VandeVoort C 2011 Similarity of bisphenol A pharmacokinetics in rhesus monkeys and mice: relevance for human exposure. Environmental Health Perspectives 119 422-430. (doi:10.1289/ehp.1002514)

Teeguarden J, Hanson-Drury S, Fisher JW \& Doerge DR 2013 Are typical human serum BPA concentrations measurable and sufficient to be estrogenic in the general population? Food and Chemical Toxicology 62 949-963. (doi:10.1016/j.fct.2013.08.001)

Ursino MG, Poluzzi E, Caramella C \& De Ponti F 2011 Excipients in medicinal products used in gastroenterology as a possible cause of side effects. Regulatory Toxicology and Pharmacology 60 93-105. (doi:10.1016/j.yrtph.2011.02.010)

Vandenberg LN, Hauser R, Marcus M, Olea N \& Welshons WV 2007 Human exposure to bisphenol A (BPA). Reproductive Toxicology 24 139-177. (doi:10.1016/j.reprotox.2007.07.010)
Vandenberg LN, Chahoud I, Heindel J, Padmanabhan V, Paumgartten F \& Schoenfelder G 2010 Urinary, circulating, and tissue biomonitoring studies indicate widespread exposure to bisphenol A. Environmental Health Perspectives 118 1055-1070. (doi:10.1289/ehp.0901716)

Vandenberg LN, Hunt PA, Myers JP \& vom Saal FS 2013 Human exposures to bisphenol A: mismatches between data and assumptions. Reviews on Environmental Health 28 37-58. (doi:10.1515/reveh-20120034)

Völkel W, Colnot T, Csanády G, Filser JG \& Dekant W 2002 Metabolism and kinetics of bisphenol $\mathrm{A}$ in humans at low doses following oral administration. Chemical Research in Toxicology 15 1281-1287. (doi:10.1021/tx025548t)

Völkel W, Kiranoglu M \& Fromme H 2008 Determination of free and total bisphenol $\mathrm{A}$ in human urine to assess daily uptake as a basis for a valid risk assessment. Toxicology Letters 179 155-162. (doi:10.1016/ j.toxlet.2008.05.002)

Williams D \& Blanchfield B 1974 Retention, excretion and metabolism of di-(2-ethylhexyl) phthalate administered orally to the rat. Bulletin of Environmental Contamination and Toxicology 11 371-378. (doi:10.1007/BF01684945)

Wittassek M, Koch HM, Angerer J \& Bruning T 2011 Assessing exposure to phthalates - the human biomonitoring approach. Molecular Nutrition \& Food Research 55 7-31. (doi:10.1002/mnfr.201000121)

Wu JL, Liu J \& Cai Z 2010 Determination of triclosan metabolites by using in-source fragmentation from high-performance liquid chromatography/ negative atmospheric pressure chemical ionization ion trap mass spectrometry. Rapid Communications in Mass Spectrometry 24 1828-1834. (doi:10.1002/rcm.4558)

Ye X, Bishop AM, Reidy JA, Needham LL \& Calafat AM 2006 Parabens as urinary biomarkers of exposure in humans. Environmental Health Perspectives 114 1843-1846. (doi:10.1289/ehp.9413)

Received 17 September 2013

First decision 7 October 2013

Revised manuscript received 5 November 2013

Accepted 28 November 2013 